\title{
NUMERICAL STUDY ON HEAT TRANSFER IN MULTILAYERED STRUCTURES OF MAIN GEOMETRIC FORMS MADE OF DIFFERENT MATERIALS
}

\author{
Roman M. Tatsiy ${ }^{1}$, Oleg Yu. Pazen ${ }^{2}$, Sergiy Ya. Vovk ${ }^{3}$, Lubomyr Ya. Ropyak ${ }^{4}$, Tetiana \\ O. Pryhorovska ${ }^{5^{*}}$
}

${ }^{1}$ Lviv State University of Life Safety, 35 Kleparivska Street, Lviv, Ukraine e-mail: r.tatsiy@ldubgd.edu.ua

${ }^{2}$ Lviv State University of Life Safety, 35 Kleparivska Street, Lviv, Ukraine e-mail: o.pazen@ldubgd.edu.ua

${ }^{3}$ Lviv State University of Life Safety, 35 Kleparivska Street, Lviv, Ukraine e-mail:s.vovk@ldubgd.edu.ua

${ }^{4}$ Ivano-Frankivsk National Technical University of Oil and Gas, 15 Karpatska Street, IvanoFrankivsk, Ukraine e-mail: 1_ropjak@ukr.net

${ }^{5}$ Ivano-Frankivsk National Technical University of Oil and Gas, 15 Karpatska Street, IvanoFrankivsk, Ukraine e-mail: pryhorovska@gmail.com

*corresponding author

\begin{abstract}
The article proposed a general research scheme of heat transfer process in multilayer constructions for three basic geometric forms in order to simulate fire distribution. The scheme is based on linear differential equations, the Fourier method and the modified method of Eigen functions. The work considers five different layers' design and does not take into account internal heat sources. In this regard, a one-parameter family of boundary problems were solved. The authors simulated heat transfer for the Cartesian, cylindrical and spherical coordinates. Structures comprised several materials each having thermal properties varying with temperature.
\end{abstract}

Keywords: boundary problem, quasi-derivative, Cauchy matrix, Fourier method, eigen function method

\section{Introduction}

Multi-layer structures, in particular composite materials, are very spread because of additional advantage of combining physical, mechanical, thermal and diffusional properties of different materials. These materials are used in civil, automotive, shipbuilding, aerospace, biomedical, power, chemical, nuclear industries and microelectronics, including design and development of buildings, pipelines, heat exchangers, multilayer insulators, fluid reservoirs, pressure vessels, filters, composite membranes, automotive, ship and aerospace components, 
nuclear reactors, etc (Gay 2015, Kumar 2017). There are numerous papers based on twodimensional thin-layer models and contain analytical and numerical estimates of thermoelastic equilibrium of bodies with layer coatings under the influence of distributed and local thermal and mechanical loading (Yasniy 2017; Yasniy 2013; Shevchuk 2013; Shevchuk 2017). Temperature stresses in bodies with surface inhomogeneities were investigated in papers by Beck (1984), Bulavin (1965), Giere (1965), Hagn (2012). Temperature effect on properties and destruction for energy equipment materials is studied by Kolesov (1992), and Malanchuk (2017).

The subject of the proposed herein article is the heat transfer and diffusion in multilayer structures. This way, a proper understanding of the internal thermal processes in the laminate structures is of paramount importance for preventing their thermal destruction, for controlling directional heat transfer through them, for analysing of thermal stresses and deformation, etc.

Therefore, it is important to have efficient procedures for heat flow and temperature distribution calculating inside multiple layers. An analytical method or numerical simulations are the most spread approaches to get the mentioned above procedures.

Practically, precise analytical solutions (if they are available) may be very mathematically complicated, and this way numerical methods like FDM (Özişik 2017), FEM (Gosz 2017), or BEM (Aliabadi 2002) become increasingly popular because of modern numerical computation and continuous improvement of computer technologies.

However, the analytical methods have some advantages compared to numerical ones:

1) They offer more reliable results and are numerically more efficient;

2) Precise analytical solutions give a deeper physical insight of the studied process than discrete numerical solutions, and show how the thermal behaviour of a multi-layer structure depends on parameters of layers;

3) Precise analytical solutions can be used within verification and comparison of various numerical methods.

These methods are well described in the classic books (Hahn 2012, Lykov 1967) and have been used by many researchers for stationary and non-stationary temperature fields in multi-layer non-uniform structures. They are the orthogonal and quasi-orthogonal expansion technique (Tittle 1965, Bulavin 1965), Green's function approach (Siegel 1999, Haji-Sheikh 2002), Laplace transform method (Giere 1965, Lu 2013), Fourier transform method (Kayhani 2012), a finite integral transform (Singh 2011), a method of separation of variables and eigen function expansion (Norouzi 2016), for instance.

The solution of heat transfer problem in multilayer structures was obtained for the Cartesian (Tittle 1965, Salt 1963, Mikhailov 2017, Beck 1984, Siegel 1999, de Monte 2002], cylindrical (Kayhani 2012, Norouzi 2016) and spherical coordinate system (Bulavin 1965, Salt 1963). From the viewpoint of partial differential equations, majority of the approaches are based on the variable separation or integral transformations. Their core is determination of eigenvalues of the corresponding boundary eigenvalue problem. However, this problem is not of traditional type because of discontinuous coefficients due to piecewise-homogeneous bodies.

To solve the problem, researchers use an effective technique, which is based on the concept of quasi-derivatives, well known in the modern theory of ordinary differential systems. The researchers (Lu 2005, Li 2012) combined this technique with the method of variable separation to construct a mixed problem solution of a mixed problem for the heat equation with piecewisecontinuous coefficients depending on the spatial coordinate over a finite interval. The aforementioned approach has the advantages to avoid the original finding procedure, which is the most difficult stage of integral transformation methods (Lykov 1967). 
The obtained results can be used, for example, in heat transfer study for a multilayer plate and hollow cylinder under conditions of perfect thermal contact between layers.

This idea has already been implemented in the works of Tatsiy (2011) and Semerak (2015). This way, there was the problem of this scheme unification for multilayer structures of any canonical form.

There are many papers devoted to analytical methods of non-stationary temperature field calculation in layered non-uniform structures. In particular, the methods of the Laplace, Fourier and Green functions have been being applied up to now to the multilayer structures (Semerak 2015, Arsenin 1974). Tikhonov (1997) proposed and substantiated a scheme of a mixed problem solution for heat equation with piecewise continuous coefficients depending on a finite interval spatial coordinate. The scheme was based on the reduction method, quasi-derivative concept, and modern theory of linear differential equation systems, Fourier method and modified method of eigen functions.

\section{Statement of the problem and its mathematical formulation}

A multilayer construction (in Cartesian, cylindrical or spherical coordinate systems) is considered. Its area is limited by surfaces $r=r_{0}$. and $r=r_{n}$, and is divided into $n$ layers.

Each layer is made of isotropic material and has its coefficient of thermal conductivity $\lambda$, specific heat capacity $c$ and density $\rho$. Temperature initial distribution function $\varphi(r)$ was specified depending on the coordinate $\mathrm{r}$ and time $\tau$. There is a convective heat exchange with the environment on the outer surfaces, that is, the third kind boundary conditions are met.

The general form of the thermal conductivity differential equations $y$ in Cartesian, cylindrical, and spherical coordinate systems (equations (1), (2) and (3) respectively) are [1,2]:

$$
\begin{gathered}
c(r) \rho(r) \frac{\partial t(r, \tau)}{\partial \tau}=\frac{\partial}{\partial r}\left(\lambda(r) \frac{\partial t(r, \tau)}{\partial r}\right) \\
c(r) \rho(r) \frac{\partial t(r, \tau)}{\partial \tau}=\frac{1}{r} \frac{\partial}{\partial r}\left(r \lambda(r) \frac{\partial t(r, \tau)}{\partial r}\right) \\
c(r) \rho(r) \frac{\partial t(r, \tau)}{\partial \tau}=\frac{1}{r^{2}} \frac{\partial}{\partial r}\left(r^{2} \lambda(r) \frac{\partial t(r, \tau)}{\partial r}\right)
\end{gathered}
$$

The only difference of these equations is the $r^{l}$ multiplier if $l=0, l=l$ and $l=2$. So, the equation (1) - (3) are combined into a one-parameter family of differential equations:

$$
c(r) \rho(r) \frac{\partial t(r, \tau)}{\partial \tau}=\frac{1}{r^{l}} \frac{\partial}{\partial r}\left(r^{l} \lambda(r) \frac{\partial t(r, \tau)}{\partial r}\right), \quad l=0,1,2
$$

$\mathrm{n}$ particular, particular, if $1=0$ is a multilayered flat construction; if $1=1$ is multilayer hollow cylinder; if $1=2$ is a multilayer hollow ball.

The third kind boundary conditions for the equation (4) are: 


$$
\left\{\begin{array}{c}
\lambda \frac{\partial t}{\partial r}\left(r_{0}, \tau\right)=\alpha_{0}\left(t\left(r_{0}, \tau\right)-\psi_{0}(\tau)\right), \\
-\lambda \frac{\partial t}{\partial r}\left(r_{n}, \tau\right)=\alpha_{n}\left(t\left(r_{n}, \tau\right)-\psi_{n}(\tau)\right),
\end{array}\right.
$$

and initial condition:

$$
t(r, 0)=\varphi(r)
$$

Where $\psi_{0}(\tau)$ and $\psi_{n}(\tau)$ - the ambient temperature outside of the near-surface heat layers, and $\alpha_{0}$ and $\alpha_{n}$ - heat transfer coefficients on the $r=r_{0}$ and $r=r_{n}$.surfaces.

The follow notations will be used: $\theta_{i}$ - the characteristic function of the semi-open interval $\left[r_{i}, r_{i+1}\right)$, that is $\theta_{i}=\left\{\begin{array}{l}1, r \in\left[r_{i}, r_{i+1}\right) \\ 0, r \notin\left[r_{i}, r_{i+1}\right)\end{array}\right.$

$\lambda(r)=\sum_{i=0}^{n-1} \lambda_{i} \theta_{i}, \quad c(r) \cdot \rho(r)=\sum_{i=0}^{n-1} c_{i} \cdot \rho_{i} \cdot \theta_{i}, \quad \varphi(r)=\sum_{i=0}^{n-1} \varphi_{i} \cdot \theta_{i}, \quad \lambda_{i}, c_{i}, \rho_{i}>0 \in R, \quad \forall i=\overline{0, n-1}$, $r^{l} \lambda t_{r}^{\prime} \stackrel{d f}{=} t^{[1]}(r, \tau)$ - quasi derivative [8], $q=\frac{t^{[1]}(r, \tau)}{r^{l}}$ - heat flow density.

The problem (4) - (6) solution is considered as the sum of two functions (the reduction method), according to Ropyak L. Ya., Shatskyi I. P., Makoviichuk M. V.:

$$
t(r, \tau)=u(r, \tau)+v(r, \tau)
$$

Any function $u(r, \tau)$ or $v(r, \tau)$ can be chosen in a special way, so another one is determined unambiguously.

\section{3. $u(r, \tau)$ function selection and the mixed task}

The function $u(r, \tau)$ is defined as a solution (quasistationary) of the boundary value problem:

$$
\begin{gathered}
\frac{1}{r^{l}}\left(r^{l} \lambda u^{\prime}\right)^{\prime}=0 \\
\left\{\begin{array}{c}
\lambda \frac{\partial u}{\partial r}\left(r_{0}, \tau\right)=\alpha_{0}\left(u\left(r_{0}, \tau\right)-\psi_{0}(\tau)\right), \\
-\lambda \frac{\partial u}{\partial r}\left(r_{n}, \tau\right)=\alpha_{n}\left(u\left(r_{n}, \tau\right)-\psi_{n}(\tau)\right),
\end{array}\right.
\end{gathered}
$$

Where $\tau$ - parameter.

The boundary conditions (9) can be rewritten as:

$$
\left\{\begin{array}{l}
\alpha_{0} r_{0}^{l} u\left(r_{0}, \tau\right)-u^{[1]}\left(r_{0}, \tau\right)=\alpha_{0} r_{0}^{l} \psi_{0}(\tau), \\
\alpha_{n} r_{n}^{l} u\left(r_{n}, \tau\right)+u^{[1]}\left(r_{n}, \tau\right)=\alpha_{n} r_{n}^{l} \psi_{n}(\tau),
\end{array}\right.
$$


Where $u^{[1]}(r, \tau) \stackrel{d f}{=} r^{l} \lambda u^{\prime}$

Based on the (7) projection, the equation (4) is rewritten as:

$$
c \rho \frac{\partial u(r, \tau)}{\partial \tau}+c \rho \frac{\partial v(r, \tau)}{\partial \tau}=\frac{1}{r^{l}} \frac{\partial}{\partial r}\left(r^{l} \lambda \frac{\partial u(r, \tau)}{\partial r}\right)+\frac{1}{r^{l}} \frac{\partial}{\partial r}\left(r^{l} \lambda \frac{\partial v(r, \tau)}{\partial r}\right)
$$

Assuming $u(r, \tau)$ is the solution of the problems (8), (10), and considering $\frac{1}{r^{l}} \frac{\partial}{\partial r}\left(r^{l} \lambda \frac{\partial u(r, \tau)}{\partial r}\right) \equiv 0$ in the (11), we receive a non-uniform differential equation for the function $v(r, \tau)$ :

$$
c \rho \frac{\partial v(r, \tau)}{\partial \tau}=\frac{1}{r^{l}} \frac{\partial}{\partial r}\left(r^{l} \lambda \frac{\partial v(r, \tau)}{\partial r}\right)-c \rho \frac{\partial u(r, \tau)}{\partial \tau}
$$

The function $-c \rho \frac{\partial u(r, \tau)}{\partial \tau}$ at the right-hand side of the equation (12) is considered defined, that is the function $u(r, \tau)$ is defined, too. The function $u(r, \tau)$ is considered (8), (10) problem solution. As far as the function $u(r, \tau)$ meets the boundary conditions (10), the projection (7) defines the boundary conditions for the function $v(r, \tau)$.

$$
\left\{\begin{array}{l}
\alpha_{0} r_{0}^{l} v\left(r_{0}, \tau\right)-v^{[1]}\left(r_{0}, \tau\right)=0 \\
\alpha_{n} r_{n}^{l} v\left(r_{n}, \tau\right)+v^{[1]}\left(r_{n}, \tau\right)=0
\end{array}\right.
$$

and the initial condition is the following:

$$
v(r, 0)=f(r) \equiv \varphi(r)-u(r, 0) .
$$

Consequently, the function $v(r, \tau)$ is the solution of the mixed problem (12) - (14), if only $u(r, \tau)$ function is defined as the (8), (10) problem solution.

\section{The (8), (10) boundary problem solving}

The quasi-derivative concept $[4,8]$ is used for the problem (8), (10) solving.

The vector $\bar{U}=\left(\begin{array}{ll}u & u^{[1]}\end{array}\right)^{T}$, and the matrix $A=\left(\begin{array}{cc}0 & \frac{1}{r^{l} \lambda} \\ 0 & 0\end{array}\right)$. are introduced. This way, the quaside-differential equation (8) is reduced to an equivalent system of 1-st order differential equations:

$$
\bar{U}^{\prime}=A \bar{U}+\bar{R}
$$

The boundary conditions (10) are presented in the vector form: 


$$
P \cdot \bar{U}\left(r_{0}\right)+Q \cdot \bar{U}\left(r_{n}\right)=\bar{\Gamma}(\tau)
$$

Where $P$ and $Q-$ square matrixes:

$$
P=\left(\begin{array}{cc}
r_{0}^{l} \alpha_{0} & -1 \\
0 & 0
\end{array}\right), \quad Q=\left(\begin{array}{cc}
0 & 0 \\
r_{n}^{l} \alpha_{n} & 1
\end{array}\right),
$$

And the vector $\bar{\Gamma}(\tau)$ is $\left(r_{0}^{l} \alpha_{0} \psi_{0}(\tau), \quad r_{n}^{l} \alpha_{n} \psi_{n}(\tau)\right)^{T}$.

The function $\bar{U}(r)$, which is absolutely continuous on the interval $\left[r_{0}, r_{n}\right]$, and fits the this system almost everywhere (the only exception is, perhaps, the function rupture points $c(r), \rho(r), \lambda(r))$.

The system (15) is:

$$
{\overline{U_{i}}}^{\prime}=A_{i} \bar{U}_{i}, \quad A_{i}=\left(\begin{array}{cc}
0 & \frac{1}{r^{l} \lambda_{i}} \\
0 & 0
\end{array}\right)
$$

for each interval.

The Cauchy matrix [4-7] $B_{i, l}(r, s)$ of the system (18) is the follows:

$$
B_{i, l}(r, s)=\left(\begin{array}{cc}
1 & K_{i, l}(r, s) \\
0 & 1
\end{array}\right), l=0,1,2
$$

where

$$
K_{i, l}(r, s)=\frac{1}{\lambda_{i}} \int_{s}^{r} \frac{d z}{z^{l}}
$$

For arbitrary $k \geq i$, it was designated

$$
B_{l}\left(r_{n}, r_{m}\right) \stackrel{d f}{=} B_{n-1, l}\left(r_{n}, r_{n-1}\right) \cdot B_{n-2, l}\left(r_{n-1}, r_{n-2}\right) \cdot \ldots \cdot B_{m, l}\left(r_{m+1}, r_{m}\right), n>m
$$

Assuming $B_{l}\left(r_{m}, r_{m}\right)=E$, where $E-$ is a $2 \times 2$. matrix.

The structure (19) of the matrices $B_{i, l}(r, s)$ makes possible to establish the matrix structure (21), in particular:

$$
B_{l}\left(r_{n}, r_{m}\right)=\left(\begin{array}{cc}
1 & \sum_{i=m}^{n-1} K_{i, l}(r, s) \\
0 & 1
\end{array}\right), n>m
$$

The work [4, 6] stated that the vector function $\bar{U}_{i}(r)$ is the solution of problem (15) for each interval.

$$
\bar{U}_{i}(r)=B_{i}\left(r, r_{i}\right) \cdot B\left(r_{i}, r_{0}\right) \cdot P_{0} \cdot \theta_{i}
$$

where 


$$
\overline{P_{0}}=\left(P+Q B_{l}\left(r_{n}, r_{0}\right)\right)^{-1} \cdot \bar{\Gamma}
$$

and the matrices are defined in (17) and the matrices $P$ and $Q$ are defined in (17).

It should be noted that the decision function $u_{i}(r)$ is the first coordinate of the vectorfunction $\bar{U}_{i}(r)$ (problem (8), (10)); and its quasi-derivative is the second coordinate $u_{i}^{[1]}(r)$. The solution (23) of the problem (8), (10) exists and is unique when the condition $\operatorname{det}\left(P+Q B_{l}\left(r_{n}, r_{0}\right)\right) \neq 0$ is fulfilled.

The expression (23) makes possible to define a solution over the entire interval $\left[x_{0}, x_{n}\right]$ using characteristic functions $\theta_{i}$ as:

$$
u(r, \tau)=\sum_{i=0}^{n-1} u_{i}(r, \tau) \theta_{i}
$$

\section{Fourier method and task for eigenvalues}

We search non-trivial partial solutions of the homogeneous differential equation:

$$
c \rho \frac{\partial v(r, \tau)}{\partial \tau}=\frac{1}{r^{l}} \frac{\partial}{\partial r}\left(r^{l} \lambda \frac{\partial v(r, \tau)}{\partial r}\right)
$$

which fulfils the boundary conditions (13), in the form [9]

$$
v(r, \tau)=e^{-\omega \tau} \cdot R(r)
$$

where $\omega$-parameter, $R(r)$ - unknown function.

The follow quasi-differential equation was obtained by substituting the right-hand side of (27) in (26):

$$
\left(r^{l} \lambda R^{\prime}\right)^{\prime}+\omega c \rho r^{l} R=0
$$

with boundary conditions:

$$
\left\{\begin{array}{l}
\alpha_{0} r_{0}^{l} R\left(r_{0}\right)-R^{[1]}\left(r_{0}\right)=0, \\
\alpha_{n} r_{n}^{l} R\left(r_{n}\right)+R^{[1]}\left(r_{n}\right)=0 .
\end{array}\right.
$$

The problem (28), (29) is a classical eigenvalue problem for $\omega$ parameter (eigenvalues) definition, which corresponds to nontrivial solutions (own functions) $R_{k}\left(r, \omega_{k}\right)$. Properties of eigenvalues $\omega_{k}$ and their own functions $R_{k}\left(r, \omega_{k}\right)$ are exhaustively studied and described in detail, for example, in [9]. 


\section{Structural construction of own functions}

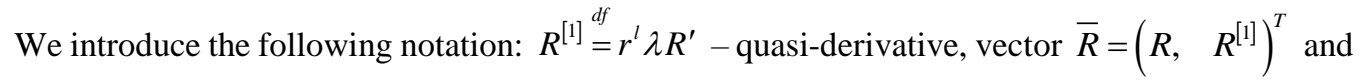
$\operatorname{matrix} A=\left(\begin{array}{cc}0 & \frac{1}{r^{l} \lambda} \\ -\omega r^{l} c \rho & 0\end{array}\right)$

Then the quasi-differential equation (28) is reduced to the system of equivalent first order differential equations:

$$
\bar{R}^{\prime}=A \bar{R}
$$

The corresponding system on the interval $\left[r_{i}, r_{i+1}\right)$ is:

$$
\bar{R}_{i}^{\prime}=A_{i} \bar{R}_{i}, \quad i=\overline{0, n-1},
$$

Where $A_{i}$ - the matrix $A_{i}=\left(\begin{array}{cc}0 & \frac{1}{r^{l} \lambda_{i}} \\ -\omega r^{l} c_{i} \rho_{i} & 0\end{array}\right)$

As it was mentioned above, absolutely continuous vector-function $\bar{R}(r, \omega)$ is the solution of the system (30), which corresponds to the conditions of the ideal thermal contact between the layers.

The Cauchy matrix $B_{i, l}(r, s, \omega)$ of the system (31) is:

$$
\begin{aligned}
& \tilde{B}_{i, l}(r, s, \omega)=
\end{aligned}
$$

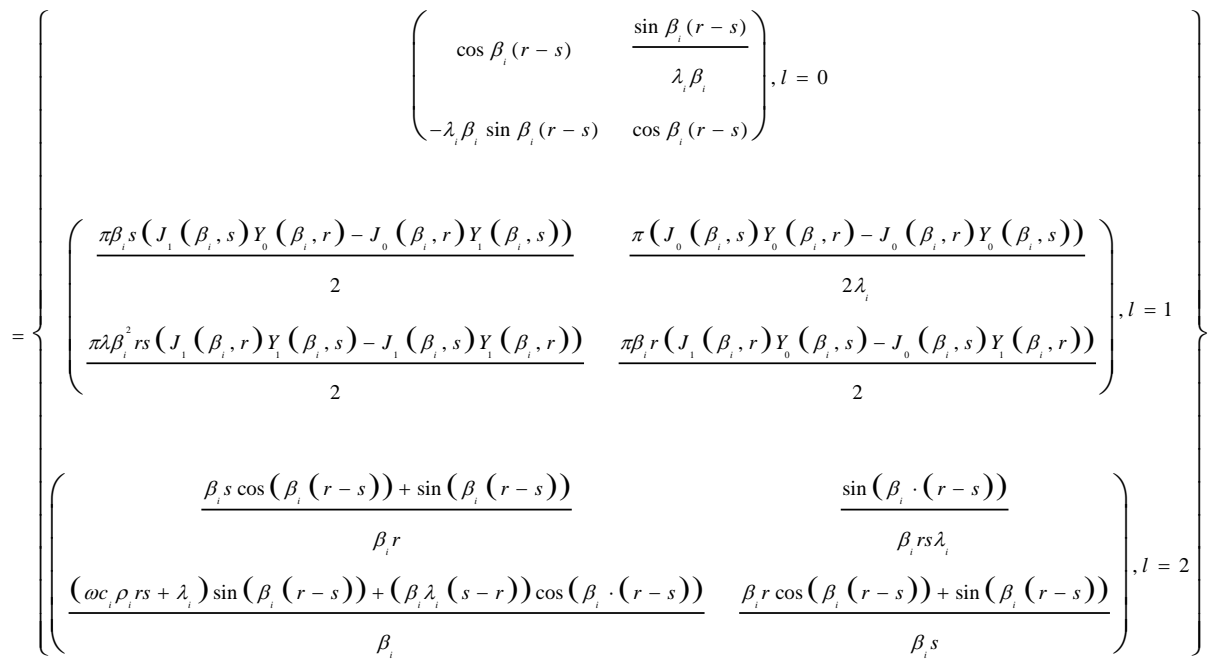

Where $\beta_{i}=\sqrt{\frac{\omega c_{i} \rho_{i}}{\lambda_{i}}}, J_{0}$ and $N_{0}$-the Bessel and Neumann functions of zero order respectively. Similarly, as in formula (21): 


$$
B\left(r_{k}, r_{i}, \omega\right) \stackrel{d f}{=} B_{k-1}\left(r_{k}, r_{k-1}, \omega\right) \cdot B_{k-2}\left(r_{k-1}, r_{k-2}, \omega\right) \cdot \ldots \cdot B_{i}\left(r_{i+1}, r_{i}, \omega\right) \quad k>i,
$$

Let's also mark

$$
\begin{gathered}
B_{l}\left(r, r_{0}, \omega\right) \stackrel{d f}{=} \sum_{i=0}^{n-1} B_{i, l}\left(r, r_{i}, \omega\right) \cdot B_{l}\left(r_{i}, r_{0}, \omega\right) \cdot \theta_{i}, \\
B_{l}\left(r_{n}, r_{0}, \omega\right) \stackrel{d f}{=}\left(\begin{array}{ll}
b_{11}(\omega) & b_{12}(\omega) \\
b_{21}(\omega) & b_{22}(\omega)
\end{array}\right) .
\end{gathered}
$$

The non-trivial solution $\bar{R}(r, \omega)$ of the system (30) is found as

$$
\bar{R}(r, \omega)=B_{l}\left(r, r_{0}, \omega\right) \cdot \bar{C}
$$

where $\bar{C}=\left(C_{1}, C_{2}\right)^{T}$ - a non-zero vector.

Applying to both parts of equality (36) boundary conditions in the form (16) for $\bar{\Gamma}(\tau) \equiv 0$, it was obtained:

$$
P \cdot \bar{R}\left(r_{0}, \omega\right)+Q \cdot \bar{R}\left(r_{n}, \omega\right)=\left[P \cdot B_{l}\left(r_{0}, r_{0}, \omega\right)+Q \cdot B_{l}\left(r_{n}, r_{0}, \omega\right)\right] \cdot \bar{C}=\overline{0},
$$

or, assuming $B_{l}\left(r_{0}, r_{0}, \omega\right)=E$, where $E$ - unit matrix:

$$
\left[P+Q \cdot B_{l}\left(r_{n}, r_{0}, \omega\right)\right] \cdot \bar{C}=\overline{0}
$$

The necessary and sufficient conditions for a nonzero vector $\bar{C}$ in (37) are:

$$
\operatorname{det}\left[P+Q \cdot B_{l}\left(r_{n}, r_{0}, \omega\right)\right]=0 .
$$

We can define the form of the left (characteristic) equation (38), considering the formulas (17) and (35)

$$
\operatorname{det}\left[P+Q \cdot B_{l}\left(r_{n}, r_{0}, \omega\right)\right]=\operatorname{det}\left[\left(\begin{array}{cc}
r_{0}^{l} \alpha_{0} & -1 \\
0 & 0
\end{array}\right)+\left(\begin{array}{cc}
0 & 0 \\
r_{n}^{l} \alpha_{n} & 1
\end{array}\right) \times\left(\begin{array}{ll}
b_{11}(\omega) & b_{12}(\omega) \\
b_{21}(\omega) & b_{22}(\omega)
\end{array}\right)\right]=0
$$

So we got the result, which we will formulate in the form of

Statement 1. The characteristic equation of the problem for eigenvalues (28), (29) has the form

$$
r_{0}^{l} \alpha_{0}\left(r_{n}^{l} \alpha_{n} b_{12}(\omega)+b_{22}(\omega)\right)+r_{n}^{l} \alpha_{n} b_{11}(\omega)+b_{21}(\omega)=0
$$

As it is known [9], the roots of the characteristic equation $\omega_{k}(39)$ are positive and different. They are the eigenvalues of the problem (28), (29).

To find a nonzero vector $\bar{C}=\left(C_{1}, C_{2}\right)^{T}$ we substitute $\omega_{k}$ in (37) instead of $\omega$. Then we come to vector equality: 


$$
\begin{aligned}
& {\left[\left(\begin{array}{cc}
r_{0}^{l} \alpha_{0} & -1 \\
0 & 0
\end{array}\right)\left(\begin{array}{cc}
0 & 0 \\
r_{n}^{l} \alpha_{n} & 1
\end{array}\right) \cdot\left(\begin{array}{ll}
b_{11}\left(\omega_{k}\right) & b_{12}\left(\omega_{k}\right) \\
b_{21}\left(\omega_{k}\right) & b_{22}\left(\omega_{k}\right)
\end{array}\right)\right] \cdot\left(\begin{array}{l}
C_{1} \\
C_{2}
\end{array}\right)=\left(\begin{array}{l}
0 \\
0
\end{array}\right), \Rightarrow} \\
& \Rightarrow\left(\begin{array}{cc}
\alpha_{0} & -1 \\
\left(r_{n}^{l} \alpha_{n} b_{11}\left(\omega_{k}\right)+b_{21}\left(\omega_{k}\right)\right) & \left(r_{n}^{l} \alpha_{n} b_{12}\left(\omega_{k}\right)+b_{22}\left(\omega_{k}\right)\right)
\end{array}\right) \cdot\left(\begin{array}{l}
C_{1} \\
C_{2}
\end{array}\right)=\left(\begin{array}{l}
0 \\
0
\end{array}\right)
\end{aligned}
$$

which is equivalent to the system of equations

$$
\left\{\begin{array}{l}
r_{0}^{l} \alpha_{0} C_{1}-C_{2}=0, \\
\left(r_{n}^{l} \alpha_{n} b_{11}\left(\omega_{k}\right)+b_{21}\left(\omega_{k}\right)\right) \cdot C_{1}+\left(r_{n}^{l} \alpha_{n} b_{12}\left(\omega_{k}\right)+b_{22}\left(\omega_{k}\right)\right) \cdot C_{2}=0 .
\end{array}\right.
$$

As far as the system determinant is equal to zero, then system (40) has non-zero solutions $C_{1} \neq 0, \quad C_{2} \neq 0 \in \mathbb{R}$. Assuming, for instance $C_{2}=1$,

$$
\bar{C}=\left(\frac{1}{r_{0}^{l} \alpha_{0}}, 1\right)^{T}
$$

By denoting a non-trivial eigenvector corresponding to its Eigen value ${ }^{\omega_{k}}$, we obtain

Statement 2. Eigenvector of the system of differential equations (30) with boundary conditions (16) for $\bar{\Gamma}(\tau) \equiv 0$, has the following structure

$$
\bar{R}_{k i}\left(r, \omega_{k}\right)=B_{i l}\left(r, r_{i}, \omega_{k}\right) \cdot B_{l}\left(r_{i}, r_{0}, \omega_{k}\right) \cdot\left(\begin{array}{c}
\frac{1}{\alpha_{0} r_{0}^{l}} \\
1
\end{array}\right), \quad i=\overline{0, n-1}
$$

Consequence. Eigen functions $R_{k}\left(r, \omega_{k}\right)$, as the first coordinates of eigenvectors $\bar{R}_{k}\left(r, \omega_{k}\right)$, can be written as:

$$
R_{k}\left(r, \omega_{k}\right)=(1,0) \cdot B_{l}\left(r, r_{0}, \omega_{k}\right) \cdot\left(\begin{array}{c}
\frac{1}{\alpha_{0} r_{0}^{l}} \\
1
\end{array}\right), \quad k=\overline{1, \infty}
$$

In particular, since $R_{k}\left(r, \omega_{k}\right)=\sum_{i=0}^{n-1} R_{k i}\left(r, \omega_{k}\right) \theta_{i}$, it follows from (43) that

$$
R_{k i}\left(r, \omega_{k}\right)=(1 ; 0) \cdot B_{i l}\left(r, r_{i}, \omega_{k}\right) \cdot B_{l}\left(r_{i}, r_{0}, \omega_{k}\right) \cdot\left(\begin{array}{c}
\frac{1}{\alpha_{0} r_{0}^{l}} \\
1
\end{array}\right), \quad i=\overline{0, n-1}
$$

7. Development in the Fourier series by Eigen functions $R_{k}\left(r, \omega_{k}\right)$

Let's assume

$$
g(r)=\sum_{i=0}^{n-1} g_{i}(r) \Theta_{i}
$$


Is a piecewise-absolutely continuous function, defined at the $\left[r_{0}, r_{n}\right]$ interval, specified by the different analytical expressions $g_{i}(r)$ on each of the interval $\left[r_{i}, r_{i+1}\right)$. In particular, the function $g(r)$ is developed in the Fourier series by its Eigen functions $R_{k}\left(r, \omega_{k}\right)$ of the problem (28), (29) [4]:

$$
g(r)=\sum_{k=1}^{\infty} g_{k} R_{k}\left(r, \omega_{k}\right)
$$

where the Fourier coefficients $g_{k}$ are calculated by the formulas

$$
g_{k}=\frac{1}{\left\|R_{k}\left(r, \omega_{k}\right)\right\|^{2}} \sum_{i=0}^{n-1} c_{i} \rho_{i} \int_{r_{i}}^{r_{i+1}} r^{l} \cdot g_{i}(r) \cdot R_{k i}\left(r, \omega_{k}\right) d r
$$

$\left\|R_{k}\right\|^{2}$ - Eigen function norm square $R_{k}\left(r, \omega_{k}\right)$, which is calculated by the formula

$$
\left\|R_{k}\left(r, \omega_{k}\right)\right\|^{2}=\sum_{i=0}^{n-1} c_{i} \rho_{i} \int_{r_{i}}^{r_{i+1}} r^{l} \cdot R_{k i}^{2}\left(r, \omega_{k}\right) d r
$$

\section{Development of a mixed problem (8), (9), (10) solution}

The Eigen function method [10] was used to solve the problem (12) - (14). It means the problem (12) - (14) is solved as

$$
v(r, \tau)=\sum_{k=1}^{\infty} T_{k}(\tau) \cdot R_{k}\left(r, \omega_{k}\right),
$$

where $T_{k}(\tau)$ - unknown functions that we will define later.

As far as $\frac{\partial u}{\partial \tau}$ is included into the right-hand side of equation (12), we will develop it in the Fourier series by its Eigen functions (43) of the boundary problems (28) - (29), and the variable $\tau$ is a parameter.

Substituting (49) into (12) and after transformations we obtain an infinite set of equations

$$
T_{k}^{\prime}(\tau)+\omega_{k} T_{k}(\tau)+u_{k}(\tau)=0, \quad k=1,2,3, \ldots
$$

where $u_{k}(\tau)$ - Fourier coefficients of development.

$$
\frac{\partial u}{\partial \tau}=\sum_{k=1}^{\infty} u_{k}(\tau) \cdot R_{k}\left(r, \omega_{k}\right)
$$

The general solution of the differential equation (50) for each $k$ is:

$$
T_{k}(t)=f_{k} \cdot e^{-\omega_{k} \tau}-\int_{0}^{\tau} e^{-\omega_{k}(\tau-s)} \cdot u_{k}(s) d s,
$$

where $f_{k}$ - Fourier coefficients of development. 


$$
f(r) \equiv \varphi(r)-u(r, 0)=\sum_{k=1}^{\infty} f_{k} R_{k}\left(r, \omega_{k}\right)
$$

Finally we obtain the solution of the mixed problem (12) - (14) as the vector-function

$$
\bar{V}(r, \tau)=\sum_{k=1}^{\infty}\left[f_{k} \cdot e^{-\omega_{k} \tau}-\int_{0}^{\tau} e^{-\omega_{k}(\tau-s)} u_{k}(s) d s\right] \cdot \bar{R}_{k}\left(r, \omega_{k}\right)=\sum_{i=0}^{n-1} \bar{V}_{i}(r, \tau) \theta_{i}
$$

where the first coordinate $v(r, \tau)$ is the desired function, and the second one $v^{[1]}(r, \tau)$ is its quasiderivative.

The solution of the mixed problem (12) - (14) is obtained in the form of a series:

$$
v_{i}(r, \tau)=\sum_{k=1}^{\infty}\left[f_{k} \cdot e^{-\omega_{k} \tau}-\int_{0}^{\tau} e^{-\omega_{k}(\tau-s)} u_{k}(s) d s\right] \cdot R_{k i}\left(r, \omega_{k}\right)
$$

on each of the interval.

Taking into account (25) and (55), we obtain the solution (7) of the problem (4) - (6)

$$
t(x, \tau)=\sum_{i=0}^{n-1}\left[u_{i}(x, \tau)+v_{i}(x, \tau)\right] \cdot \theta_{i},
$$

\section{Numerical implementation of the method (model example)}

As a numerical example, we consider a construction that consists of five different layers. There is a convection heat exchange with the environment on its surfaces. It is necessary to determine the distribution of the non-stationary temperature field of the five-layer structure (for Cartesian, cylindrical and spherical coordinate systems), if, on the one hand, the temperature changes according to the law of the standard fire temperature regime (Buketov A V, Dolgov NA, Sapronov A A et al.). At the initial time, temperature is constant $20^{\circ} \mathrm{C}$. The thermophysical characteristics of the materials and the laws of temperature change are given in Table 1. 


\begin{tabular}{|c|c|c|c|c|c|}
\hline Option & Layer 1 & Layer 2 & Layer 3 & Layer 4 & Layer 5 \\
\hline Thickness, $[\mathrm{m}]$ & 0.05 & 0.2 & 0.03 & 0.06 & 0.01 \\
\hline $\begin{array}{c}\text { Coefficient of thermal } \\
\text { conductivity }\left[\mathrm{W} / \mathrm{m}^{2} \cdot{ }^{0} \mathrm{C}\right]\end{array}$ & 0.76 & 1.92 & 0.09 & 0.7 & 0.96 \\
\hline Specific heat $\left[\mathrm{J} / \mathrm{kg}^{0} \mathrm{C}\right]$ & 840 & 840 & 840 & 840 & 880 \\
\hline Density & 1800 & 2500 & 300 & 1600 & 2000 \\
\hline $\begin{array}{c}\text { Temperature change laws } \\
\text { Soefficients of heat transfer } \\
\text { on surfaces }\end{array}$ & $\psi_{0}(\tau)=20, \psi_{n}(\tau)=345 \lg \left(1+\frac{8 \tau}{60}\right)+20$ \\
\hline \begin{tabular}{c} 
Con \\
\hline
\end{tabular} & $\alpha_{0}=25, \alpha_{n}=4$ \\
\hline
\end{tabular}

Table 1. Initial data for problem solving

We have obtained non-stationary temperature field problem solution for the five-layer construction for different coordinate systems by the proposed method.

Cartesian coordinate system (five-layer flat wall)
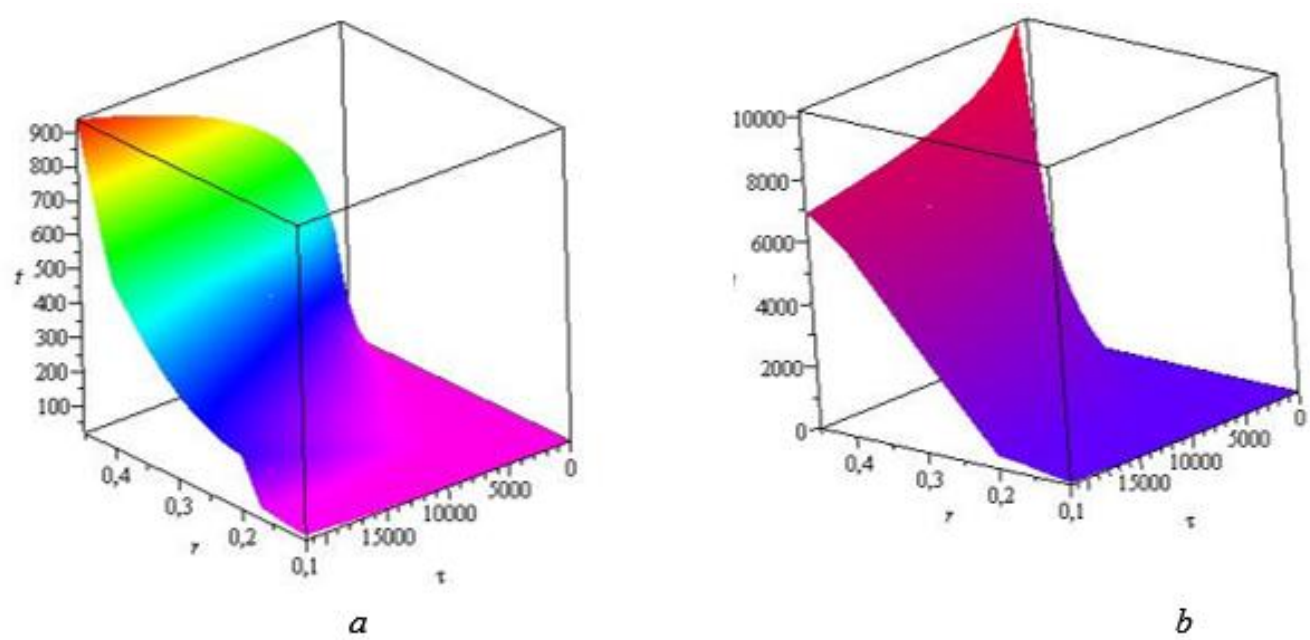

Fig. 1. Volume distribution: a - temperature field; b - heat flow density 


\begin{tabular}{|c|c|c|c|c|c|c|c|c|c|c|}
\hline \multirow[b]{2}{*}{ time } & \multicolumn{10}{|c|}{ Coordinates of the layer, $\mathrm{m}$} \\
\hline & 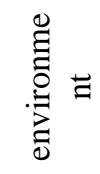 & 0.1 & 0.15 & 0.2 & 0.25 & 0.3 & 0.35 & 0.4 & 0.45 & 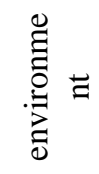 \\
\hline 0 & 20.00 & 20.00 & 20.00 & 20.00 & 20.00 & 20.00 & 20.00 & 20.00 & 20.00 & 20.00 \\
\hline $1 \mathrm{~min}$ & 20.00 & 20.00 & 20.00 & 20.00 & 20.00 & 20.00 & 20.00 & 20.00 & 68.04 & 349.2 \\
\hline $3 \mathrm{~min}$ & 20.00 & 20.00 & 20.00 & 20.00 & 20.00 & 20.00 & 20.00 & 20.00 & 133.8 & 502.2 \\
\hline $5 \min$ & 20.00 & 20.00 & 20.00 & 20.00 & 20.00 & 20.00 & 20.02 & 20.07 & 182 & 576.4 \\
\hline $30 \mathrm{~min}$ & 20.00 & 20.00 & 20.00 & 20.00 & 20.00 & 20.33 & 25.32 & 64.05 & 454.9 & 841.8 \\
\hline 1 hour & 20.00 & 20.00 & 20.00 & 20.18 & 21.15 & 27.48 & 54.95 & 139.6 & 589.5 & 945.3 \\
\hline 2 hours & 20.00 & 20.10 & 20.37 & 29.12 & 37.53 & 66.71 & 132.6 & 255.5 & 722.7 & 1049 \\
\hline 6 hours & 20.00 & 35.32 & 46.06 & 179.3 & 207.4 & 271.3 & 372.4 & 510.9 & 937.7 & 1213 \\
\hline
\end{tabular}

Table 2. Distribution of the temperature field of a five-layer flat structure, ${ }^{0} \mathrm{C}$

\begin{tabular}{|l|l|l|l|l|l|l|l|l|}
\hline \multirow{3}{*}{ time } & \multicolumn{7}{|c|}{ Coordinates of the layer, $\mathrm{m}$} \\
\cline { 2 - 10 } & 0.1 & 0.15 & 0.2 & 0.25 & 0.3 & 0.35 & 0.4 & 0.45 \\
\hline 0 & 0 & 0 & 0 & 0 & 0 & 0 & 0 & 0 \\
\hline 1 min & 0 & 0 & 0 & 0 & 0 & 0 & 0 & 7029 \\
\hline 3 min & 0 & 0 & 0 & 0 & 0 & 0 & 0 & 9211 \\
\hline 5 min & 0 & 0 & 0 & 0 & 0 & 1.7 & 16.48 & 9860 \\
\hline 30 min & 0 & 0 & 0 & 0 & 41.6 & 496.5 & 3057 & 9673 \\
\hline 1 hour & 0 & 0 & 1.6 & 90.8 & 490.5 & 1854 & 4978 & 8896 \\
\hline 2 hours & 0.2 & 8.8 & 37.7 & 646.9 & 1700 & 3498 & 6039 & 8159 \\
\hline 6 hours & 61.1 & 252 & 410.8 & 1754 & 3161 & 4605 & 6024 & 6898 \\
\hline
\end{tabular}

Table 3. Distribution of the density of the heat flow of a five-layer flat construction, $\mathrm{W} / \mathrm{m}^{2}$ 


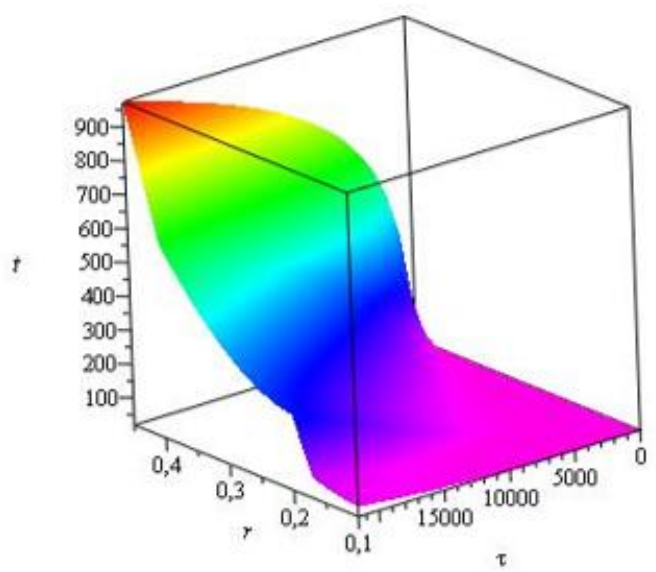

a)

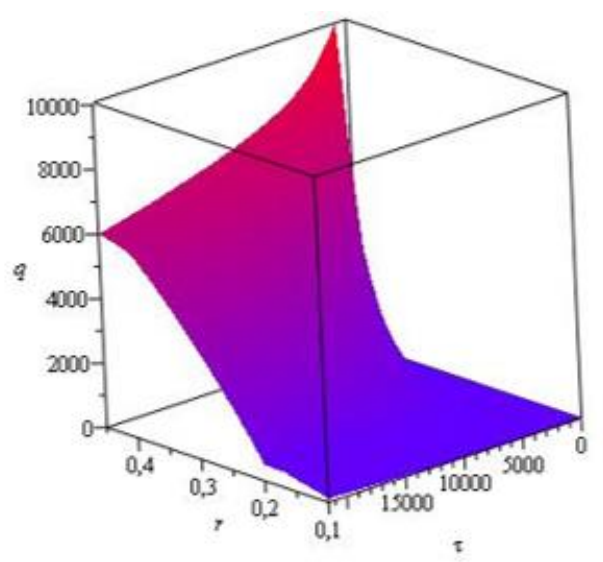

b)

Fig. 2. Volume distribution: a - temperature field; b - heat flow density

\begin{tabular}{|c|c|c|c|c|c|c|c|c|c|c|}
\hline \multirow[b]{2}{*}{ time } & \multicolumn{10}{|c|}{ Coordinates of the layer, $\mathrm{m}$} \\
\hline & 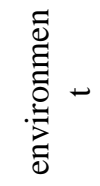 & 0.1 & 0.15 & 0.2 & 0.25 & 0.3 & 0.35 & 0.4 & 0.45 & 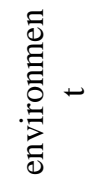 \\
\hline 0 & 20.00 & 20.00 & 20.00 & 20.00 & 20.00 & 20.00 & 20.00 & 20.00 & 20.00 & 20.00 \\
\hline $1 \mathrm{~min}$ & 20.00 & 20.00 & 20.00 & 20.00 & 20.00 & 20.00 & 20.00 & 20.00 & 68.19 & 349.2 \\
\hline $3 \mathrm{~min}$ & 20.00 & 20.00 & 20.00 & 20.00 & 20.00 & 20.00 & 20.00 & 20.00 & 134.6 & 502.2 \\
\hline $5 \mathrm{~min}$ & 20.00 & 20.00 & 20.00 & 20.00 & 20.00 & 20.00 & 20.00 & 20.08 & 183.4 & 576.4 \\
\hline $30 \mathrm{~min}$ & 20.00 & 20.00 & 20.00 & 20.00 & 20.00 & 20.39 & 26.15 & 67.96 & 462.3 & 841.8 \\
\hline 1 hour & 20.00 & 20.00 & 20.00 & 20.48 & 21.64 & 29.5 & 61.03 & 151.9 & 601.6 & 945.3 \\
\hline 2 hours & 20.00 & 20.13 & 20.58 & 33.48 & 44.44 & 80.04 & 154.4 & 283.8 & 741.4 & 1049 \\
\hline 6 hours & 20.00 & 49.68 & 67.09 & 243.9 & 277.2 & 348.3 & 453.1 & 587.6 & 973.7 & 1213 \\
\hline
\end{tabular}

Table 4. Distribution of the temperature field of a five-layer cylindrical structure, ${ }^{0} \mathrm{C}$ 


\begin{tabular}{|l|l|l|l|l|l|l|l|l|}
\hline \multirow{2}{*}{ time } & \multicolumn{7}{|c|}{ Coordinates of the layer, m } \\
\cline { 2 - 10 } & 0.1 & 0.15 & 0.2 & 0.25 & 0.3 & 0.35 & 0.4 & 0.45 \\
\hline 0 & 0 & 0 & 0 & 0 & 0 & 0 & 0 & 0 \\
\hline $1 \mathrm{~min}$ & 0 & 0 & 0 & 0 & 0 & 0 & 0 & 7023 \\
\hline $3 \mathrm{~min}$ & 0 & 0 & 0 & 0 & 0 & 0 & 0 & 9192 \\
\hline 5 min & 0 & 0 & 0 & 0 & 0 & 0 & 19.65 & 9824 \\
\hline 30 min & 0 & 0 & 0 & 0 & 50.3 & 560.1 & 3222 & 9487 \\
\hline 1 hour & 0 & 0 & 2.51 & 119 & 590.4 & 2069 & 5193 & 8593 \\
\hline 2 hours & 1.5 & 14.5 & 51.76 & 829.8 & 2001 & 3820 & 6170 & 7692 \\
\hline 6 hours & 118.8 & 377.3 & 504.9 & 2040 & 3401 & 4623 & 5678 & 5996 \\
\hline
\end{tabular}

Table 5. Distribution of the temperature field of a five-layer cylindrical structure, ${ }^{0} \mathrm{C}$

\section{Spherical coordinate system (five-layer hollow sphere)}

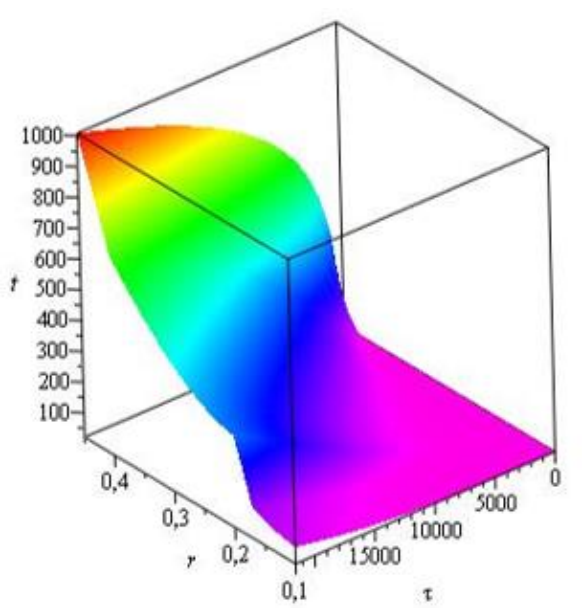

a)

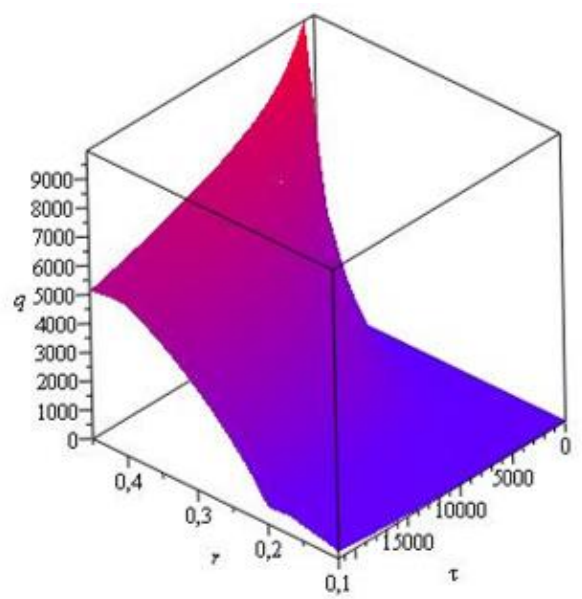

b)

Fig. 3. Volume distribution: a - temperature field; B - heat flow density 


\begin{tabular}{|c|c|c|c|c|c|c|c|c|c|c|}
\hline \multirow[b]{2}{*}{ time } & \multicolumn{10}{|c|}{ Coordinates of the layer, $\mathrm{m}$} \\
\hline & $\begin{array}{l}\text { environme } \\
\mathrm{nt}\end{array}$ & 0.1 & 0.15 & 0.2 & 0.25 & 0.3 & 0.35 & 0.4 & 0.45 & $\begin{array}{c}\text { environme } \\
\text { nt }\end{array}$ \\
\hline 0 & 20.00 & $\begin{array}{l}20.0 \\
0\end{array}$ & $\begin{array}{l}20.0 \\
0\end{array}$ & $\begin{array}{l}20.0 \\
0\end{array}$ & $\begin{array}{l}20.0 \\
0\end{array}$ & $\begin{array}{l}20.0 \\
0\end{array}$ & $\begin{array}{l}20.0 \\
0\end{array}$ & $\begin{array}{l}20.0 \\
0\end{array}$ & $\begin{array}{l}20.0 \\
0\end{array}$ & 20.00 \\
\hline $\begin{array}{l}1 \\
\min \end{array}$ & 20.00 & $\begin{array}{l}20.0 \\
0 \\
\end{array}$ & $\begin{array}{l}20.0 \\
0 \\
\end{array}$ & $\begin{array}{l}20.0 \\
0 \\
\end{array}$ & $\begin{array}{l}20.0 \\
0 \\
\end{array}$ & $\begin{array}{l}20.0 \\
0 \\
\end{array}$ & $\begin{array}{l}20.0 \\
0 \\
\end{array}$ & $\begin{array}{l}20.0 \\
0 \\
\end{array}$ & $\begin{array}{l}68.3 \\
9 \\
\end{array}$ & 349.2 \\
\hline $\begin{array}{l}3 \\
\min \end{array}$ & 20.00 & $\begin{array}{l}20.0 \\
0\end{array}$ & $\begin{array}{l}20.0 \\
0\end{array}$ & $\begin{array}{l}20.0 \\
0\end{array}$ & $\begin{array}{l}20.0 \\
0\end{array}$ & $\begin{array}{l}20.0 \\
0\end{array}$ & $\begin{array}{l}20.0 \\
0\end{array}$ & $\begin{array}{l}20.0 \\
0\end{array}$ & $\begin{array}{l}135 . \\
4\end{array}$ & 502.2 \\
\hline $\begin{array}{l}5 \\
\min \end{array}$ & 20.00 & $\begin{array}{l}20.0 \\
0\end{array}$ & $\begin{array}{l}20.0 \\
0\end{array}$ & $\begin{array}{l}20.0 \\
0\end{array}$ & $\begin{array}{l}20.0 \\
0\end{array}$ & $\begin{array}{l}20.0 \\
0\end{array}$ & $\begin{array}{l}20.0 \\
0\end{array}$ & $\begin{array}{l}20.0 \\
6\end{array}$ & $\begin{array}{l}184 . \\
8\end{array}$ & 576.4 \\
\hline $\begin{array}{l}30 \\
\min \end{array}$ & 20.00 & $\begin{array}{l}20.0 \\
0 \\
\end{array}$ & $\begin{array}{l}20.0 \\
0\end{array}$ & $\begin{array}{l}20.0 \\
0 \\
\end{array}$ & $\begin{array}{l}20.0 \\
0\end{array}$ & $\begin{array}{l}20.5 \\
1\end{array}$ & $\begin{array}{l}27.0 \\
9 \\
\end{array}$ & $\begin{array}{l}72.0 \\
9 \\
\end{array}$ & $\begin{array}{l}469 . \\
7 \\
\end{array}$ & 841.8 \\
\hline $\begin{array}{l}1 \\
\text { hour }\end{array}$ & 20.00 & $\begin{array}{l}20.0 \\
0\end{array}$ & $\begin{array}{l}20.1 \\
8\end{array}$ & $\begin{array}{l}20.7 \\
8\end{array}$ & $\begin{array}{l}22.1 \\
7\end{array}$ & $\begin{array}{l}31.8 \\
6\end{array}$ & $\begin{array}{l}67.8 \\
3\end{array}$ & $\begin{array}{l}164 . \\
8\end{array}$ & $\begin{array}{l}613 . \\
7\end{array}$ & 945.3 \\
\hline $\begin{array}{l}2 \\
\text { hour } \\
\text { s }\end{array}$ & 20.00 & $\begin{array}{l}20.4 \\
3\end{array}$ & $\begin{array}{l}21.1 \\
5\end{array}$ & $\begin{array}{l}39.2 \\
5\end{array}$ & $\begin{array}{l}53.3 \\
6\end{array}$ & 96 & $\begin{array}{l}178 . \\
8\end{array}$ & $\begin{array}{l}313 . \\
7\end{array}$ & $\begin{array}{l}760 . \\
1\end{array}$ & 1049 \\
\hline $\begin{array}{l}6 \\
\text { hour } \\
\text { s }\end{array}$ & 20.00 & $\begin{array}{l}73.7 \\
7\end{array}$ & $\begin{array}{l}99.9 \\
2\end{array}$ & 320 & $\begin{array}{l}358 . \\
1\end{array}$ & $\begin{array}{l}433 . \\
8\end{array}$ & $\begin{array}{l}538 . \\
5\end{array}$ & $\begin{array}{l}665 . \\
6\end{array}$ & $\begin{array}{l}100 \\
8\end{array}$ & 1213 \\
\hline
\end{tabular}

Table 6. Distribution of the temperature field of a five-layer hollow sphere, ${ }^{0} \mathrm{C}$

\begin{tabular}{|l|l|l|l|l|l|l|l|l|}
\hline \multirow{3}{*}{ time } & \multicolumn{7}{|c|}{ Coordinates of the layer, m } \\
\cline { 2 - 10 } & 0.1 & 0.15 & 0.2 & 0.25 & 0.3 & 0.35 & 0.4 & 0.45 \\
\hline 0 & 0 & 0 & 0 & 0 & 0 & 0 & 0 & 0 \\
\hline 1 min & 0 & 0 & 0 & 0 & 0 & 0 & 0 & 7022 \\
\hline 3 min & 0 & 0 & 0 & 0 & 0 & 0 & 0 & 9172 \\
\hline 5 min & 0 & 0 & 0 & 0 & 0 & 0 & 18.61 & 9790 \\
\hline 30 min & 0 & 0 & 0 & 0 & 61.35 & 628.5 & 3389 & 9301 \\
\hline 1 hour & 0 & 1.2 & 3.01 & 154.7 & 704.3 & 2294 & 5399 & 8290 \\
\hline 2 hours & 1.4 & 22.7 & 68.73 & 1041 & 2316 & 4124 & 6259 & 7226 \\
\hline 6 hours & 214.8 & 526.2 & 584.4 & 2256 & 3509 & 4491 & 5229 & 5129 \\
\hline
\end{tabular}

Table 7. Distribution of heat density of a five-layer hollow ball, $\mathrm{W} / \mathrm{m}^{2}$

\section{Conclusions}

This paper proposes a heat transfer scheme for multilayer constructions of various geometric forms. The authors obtained a non-stationary temperature field problem solution for the five-layer construction for different coordinate systems by the proposed method. The boundary conditions of the third kind are considered to make it clearer. The proposed scheme makes other boundary condition consideration easy. The work does not take into account internal heat sources to avoid calculation complications, which can divert attention from the main idea of the proposed approach. The method makes possible application of other external surface temperature changing 
relations. The presented examples use only the standard temperature mode of fire to show the proposed method application. The obtained analytical solution is modelled as a pseudocode and implemented on a specific numerical example.

Acknowledgements The authors are grateful to all the teams of Ivano-Frankivsk National University of Oil and Gas (Ukraine) and Lviv State University of Life Safety for sharing their pearls of wisdom of this research, and thanks the reviewers for their insights.

\section{References}

Aliabadi M H (2002). The Boundary Element Method, Applications in Solids and Structures, John Wiley \& Sons, 598.

Arsenin V Ya (1974). Methods of Mathematical Physics and Special Functions, Nauka, Moscow. Beck J V (1984). Green's Function Solution for Transient Heat Conduction Problems, Int. J. Heat Mass Transfer, Vol. 27, Issue 8. 1235-1244.

Buketov A V, Dolgov N A, Sapronov A A et al (2017). Mechanical Characteristics of Epoxy Nanocomposite Coatings with Ultradisperse Diamond Particles. Strength Mater, 49, 464471.

Bulavin P E, Kascheev V M (1965). Solution of the non-homogeneous heat conduction equation for multilayered bodies, Int. Chem. Eng, Vol. 1, Issue 5, 112-115.

Dolgov M A, Zubrets'ka N A, Buketov A V et al. (2012). Use of the method of mathematical experiment planning for evaluating adhesive strength of protective coatings modified by energy fields, Strength Mater, 44(1), 81-86.

EN 1991-1-2 (2002). (English): Eurocode 1: Actions on structures - Part 1-2: General actions Actions on structures exposed to fire Authority: The European Union Per Regulation 305/2011, Directive 98/34/EC, Directive 2004/18/EC.

Gay, D (2015). Composite Materials: Design and Application, 3rd Edition. New York: CRC Press, 635

Giere A C (1965). Transient Heat Flow in a Composite Slab - Constant Flux, Zero Flux Boundary Conditions, Appl. Sci. Research, Section A, Vol. 14, Issue 1, 191-198.

Gosz M R (2017). Finite Element Method: Applications in Solids, Structures, and Heat Transfer, New York: CRC Press, 400.

Hahn D W, Özişik M N (2012). Heat Conduction, New York: John Wiley \& Sons, 744.

Haji-Sheikh A, Beck J V (2002). Temperature solution in multidimensional multi-layer bodies, Int. J. Heat Mass Transfer, Vol. 45, Issue 9, 1865-1877.

Jain P.K., Singh S., Rizwan-uddin (2010). An exact analytical solution for twodimensional, unsteady, multilayer heat conduction in spherical coordinates, Int. J. Heat Mass Transfer, Vol. 53, Issue 9-10, 2133-2142.

Kayhani M H, Norouzi M, Amiri Delouei A (2012). A general analytical solution for heat conduction in cylindrical multilayer composite laminates, Int. J. Therm. Sci, Vol. 52, Issue $1,73-82$.

Kolesov V S, Vlasov N M, Tisovskii L O, Shatskii I P (1992). The stress-deformation state of an elastic half-space with a spheroidal thermal inclusion, International Applied Mechanics, 28(7), 426-434.

Kolodziejczyk W, Kul'chyts'kyi-Zhyhailo R (2007). Pressure of the lateral surface of a cylinder on a periodically layered half space. Mater Sci, 43, 351-360.

Kolyano Yu M, Protsyuk B V, Sinyuta V M, Shebanov S M, Sharov S M (1992). Non-stationary temperature field in a multilayer orthotropic cylinder, Engineering Physics Journal, Vol. 62, Issue 2, 325-330. 
Kul'chyts'kyi-Zhyhailo, R.D. (2012). Elastic half space with laminated coating of periodic structure under the action of Hertz's pressure. Mater Sci, 47: 527-534.

Kumar M (2017). Applications of Composite Materials, Arcler Education Incorporated, 273.

Li M, Lai A C K (2013). Analytical solution to heat conduction in finite hollow composite cylinders with a general boundary condition, Int. J. Heat and Mass Transfer, Vol. 60, 549556.

Lu X, Tervola P, Viljanen M (2005). A new analytical method to solve heat equation for multidimensional composite slab, J. Phys. A: Math. Gen, Vol. 38, Issue 13, 2873-2890.

Lu X, Tervola P, Viljanen M (2006). Transient analytical solution to heat conduction in composite circular cylinder, Int. J. Heat Mass Transfer, Vol. 49, Issue 1-2, 341-348.

Lykov A V (1967). Heat Conduction Theory, Moscow: Vysshaya Shkola.

Malanchuk N I, Slobodyan B S, Martynyak R M (2017). Friction Sliding of Elastic Bodies in the Presence of Subsurface Inclusions, Mater Sci, 52, 819-826.

Mikhailov M D, Özişik M N (2017). Transient conduction in a three-dimensional composite slab, Int. J. Heat Mass Transfer, Vol. 29, Issue 2, 340-342.

Monte F de (2002). An analytic approach to the unsteady heat conduction processes in onedimensional composite media, Int. J. Heat Mass Transfer, Vol. 45, Issue 6, 1333-1343.

Monte F de (2003). Unsteady heat conduction in two-dimensional two slab-shaped regions. Exact closed-form solution and results, Int. J. Heat Mass Transfer, Vol. 46, Issue 8, 1455-1469.

Norouzi M, Rahmani H, Birjandi A K, Joneidi A A (2016). A general exact analytical solution for anisotropic non-axisymmetric heat conduction in composite cylindrical shells, Int. J. Heat Mass Transfer, Vol. 93, 41-56.

Özişik M N, Orlande H R B, Colaço M J, Cotta R M (2017). Finite Difference Methods in Heat Transfer, Second Edition. New York: CRC Press, 580.

Ropyak L Ya, Shatskyi I P, Makoviichuk M V (2017). Influence of the oxide-layer thickness on the ceramic-aluminium coating resistance to indentation. Metallofizika $i$ Noveishie Tekhnologii. 2017. 39(4): 517-524.

Salt H (1983). Transient conduction in a two-dimensional composite slab-I. Theoretical development of temperature modes, Int. J. Heat Mass Transfer, Vol. 26, Issue 11, 16111616.

Semerak M M, Tatsii R M, Pazen O Y (2015). Multilayer thermal insulation capacity construction with regard to damage arbitrary layer, Vestnik Kokshetauskogo tekhnicheskogo instituta, Issue 4, 8-17.

Shats'kyi I P, Ropyak L Y, Makoviichuk M V (2016). Strength optimization of a two-layer coating for the particular local loading conditions, Strength of Materials, 48(5), 726-730.

Shevchuk V A (2017). Thermoelasticity problem for a multilayer coating/half-space assembly with undercoat crack subjected to convective thermal loading. Journal of Thermal Stresses, 40(10), 1215-1230.

Shevchuk V A (2013). Analytical solution of nonstationary heat conduction problem for a halfspace with a multilayer coating, J Eng Phys Thermophy, 86(1), 450-459.

Siegel R (1999). Transient thermal analysis of parallel translucent layers by using Green's functions, J. Thermophys. Heat Transfer (AIAA), Vol. 13, Issue 1, 10-17.

Singh S, Jain P K, Rizwan-uddin (2011). Finite integral transform method to solve asymmetric heat conduction in a multilayer annulus with time-dependent boundary conditions, Nucl. Eng. Des, Vol. 241, Issue 1, 144-154.

Tatsii R M, Stasiuk M F, Mazurenko V.V, Vlasii O O (2011). Generalized equation kvazidyferentsialni, Prepr./AN Ukraini IPPMM; No 2-94, 1-4.

Tatsiy R. M., Pazen O. Y. (2015). Direct method for calculating a non-stationary temperature field under fire conditions, Pozhezhna bezpeka: Zb. nauk. Pr, Lviv: LDU BZHD, Issue 26, $135-141$. 
Tatsiy R M, Pazen O Y (2016) General boundary-value problems for the heat conduction equation with piecewise-continuous coefficients, Journal of Engineering Physics and Thermophysics, Vol. 89, Issue 2, 357-368.

Tatsiy R M, Stasiuk M F, Vlasii O O, Pazen O Yu (2017) The direct method of studying the temperature field in a multilayer pipeline under fire conditions, Information Technologies and Computer Modeling, Collection of articles of the International scientific and practical conference, May 15-20, 436-440.

Tikhonov A N, Samarskii A A (1977) Mathematical physics equation, Nauka, Moscow, 735.

Tittle CW (1965). Boundary value problems in composite media: quasiorthogonal functions, $J$. Appl. Phys, Vol. 36, Issue 4, 1486-1488.

Tokovyy Y., Ma C.-C. (2015) Analytical solutions to the axisymmetric elasticity and thermoelasticity problems for an arbitrarily inhomogeneous layer, International Journal of Engineering Science, 92 (1), 1-17.

Yasniy O, Pyndus Yu, Yasniy V, Lapusta Y (2017). Residual lifetime assessment of thermal power plant superheater header, Engineering Failure Analysis, 82(10), 390-403.

Yasniy O, Vuherer T, Yasniy V, Sobchak A. (2013). Mechanical behaviour of material of thermal power plant steam superheater collector after exploitation, Engineering Failure Analysis, 27(1), 262-271

Yasniy V, Maruschak P, Yasniy O. Lapusta Y (2013). On thermally induced multiple cracking of a surface: An experimental study, International Journal of Fracture, 181(2), 293-300. 